\title{
Effect of atropine on proximal gastric motor and sensory function in normal subjects
}

\author{
I Lidums, G S Hebbard, R H Holloway
}

\begin{abstract}
Background and aims-Distension of the proximal stomach is a major stimulus for triggering transient lower oesophageal sphincter (LOS) relaxations. We have shown recently that atropine inhibits triggering of transient LOS relaxations in both normal subjects and patients with gastro-oesophageal reflux disease. Atropine could potentially act centrally by inhibiting the central integrating mechanism in the brain stem, or act peripherally by altering the response of the stomach to distension. The aim of this study was to investigate the effect of atropine on fasting gastric compliance and postprandial gastric tone using an electronic barostat.
\end{abstract}

Methods-Fasting and postprandial proximal gastric motor and sensory functions were assessed in $\mathbf{1 0}$ normal healthy volunteers. Oesophageal manometry and pH were simultaneously measured. On separate days, atropine $(15 \mu \mathrm{g} / \mathrm{kg}$ bolus, 4 $\mu \mathrm{g} / \mathrm{kg} / \mathrm{h}$ intravenous infusion) or saline was given and maintained for the duration of the recording period.

Results-In the fasting period, atropine significantly reduced minimum distending pressure $(5.5(0.4) v 4.4(0.4) \mathrm{mm} \mathrm{Hg}$; $\mathrm{p}<0.005)$ and increased proximal gastric compliance $(81.3(5.3) \quad v 102.1$ (8.7) $\mathrm{ml} /$ $\mathrm{mm} \mathrm{Hg} ; \mathrm{p}<0.05)$. In response to a meal, maximal gastric relaxation was similar on both study days. However, during atropine infusion, there was no recovery of proximal gastric tone in the two hour postprandial observation period. Postprandial fullness scores were higher during atropine infusion and correlated with changes in intrabag volume. Atropine significantly reduced the rate of postprandial transient LOS relaxations: first hour, 7.0 (5.3-10.0) $v 3.0(1.0-4.0)(\mathrm{p}<0.02)$; second hour, 5.0 (3.3-5.8) per hour $v 1.0(0-3.0)$ per hour $(\mathbf{p}<0.05)$.

Conclusions-In humans, fasting and postprandial proximal gastric motor function is under cholinergic control. Atropine induced inhibition of transient LOS relaxations is unlikely to be caused by its effect on the proximal stomach, but rather by a central action on the integrating mechanisms in the brain stem. (Gut 2000;47:30-36)

Keywords: barostat; compliance; gastric fundus; atropine
Transient lower oesophageal sphincter (LOS) relaxation is the predominant mechanism of gastro-oesophageal reflux in normal subjects ${ }^{1}$ and in the majority of patients with gastrooesophageal reflux disease. ${ }^{2-4}$ Distension of the proximal stomach is a major stimulus for triggering transient LOS relaxations. ${ }^{56} \mathrm{We}$ have shown recently that atropine substantially inhibits gastro-oesophageal reflux in normal subjects $^{7}$ and in patients with gastrooesophageal reflux disease, ${ }^{8}$ predominantly by inhibition of transient LOS relaxations. The site at which atropine exerts this effect, however, is not known.

Current evidence suggests that gastric distension stimulates transient LOS relaxations via a vagal reflex pathway that is integrated in the brain stem. ${ }^{9}$ Atropine could potentially act at two sites: centrally, by inhibiting the central integrating mechanisms in the brain stem that are believed to mediate transient LOS relaxations; or peripherally, by altering the mechanical properties of the proximal stomach.

Data on the effect of atropine on motor and sensory functions of the proximal stomach are limited and findings have varied among studies. In dogs and cats, atropine reduces fasting proximal gastric tone. ${ }^{10-12}$ In humans, however, atropine has not been shown to have any significant effect on fasting or postprandial proximal gastric tone. ${ }^{13}{ }^{14}$ The aim of this study, therefore, was to further investigate the effect of atropine on proximal gastric motor and sensory functions using an electronic barostat in normal subjects in both the fasted and postprandial states, to gain further insight into the mechanism by which atropine inhibits transient LOS relaxations.

\section{Methods}

SUBJECTS

Studies were performed in 10 healthy subjects (eight males, two females) aged 19-39 years (median 25). Subjects were free of gastrointestinal symptoms, had no history of upper gastrointestinal surgery, and were not taking regular antacids or medications known to influence oesophageal or gastric motor function. Each subject gave written informed consent and the protocol was approved by the Research Ethics Committee of the Royal Adelaide Hospital.

RECORDING METHODS

Oesophageal motility was measured using a multilumen manometric assembly with an

Abbreviations used in this paper: LOS, lower oesophageal sphincter; MDP, minimum distending pressure: ID, internal diameter. 


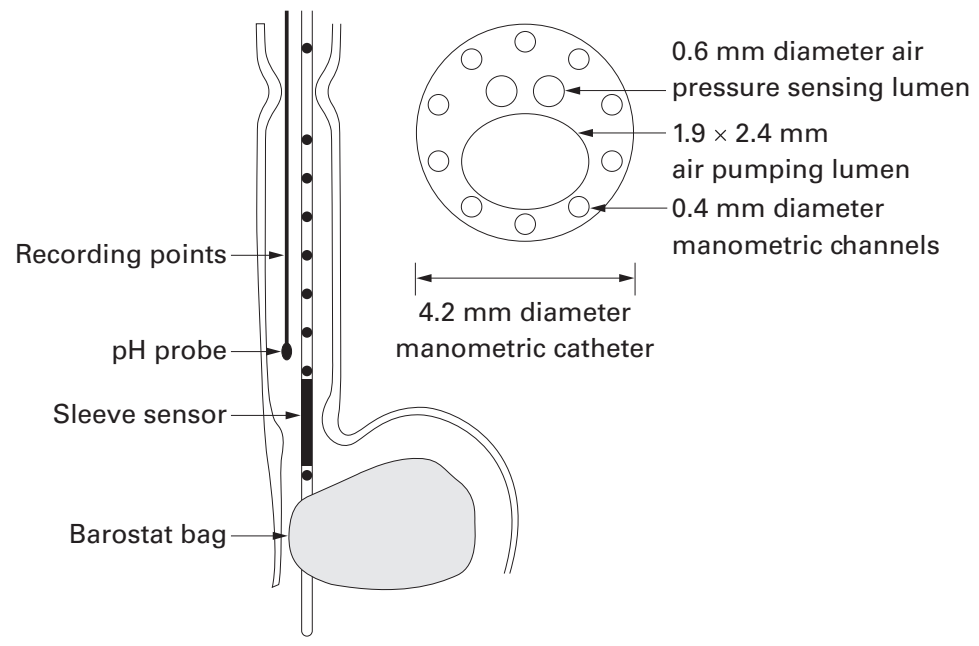

Figure 1 Diagrammatic illustration of the combined manometric and barostat assembly (left) and a cross sectional view of the assembly (right).

outer diameter of $4.2 \mathrm{~mm}$ (fig 1). LOS pressure was measured with a reverse perfused sleeve sensor. ${ }^{15}$ Gastric pressure was recorded using a side hole located $10 \mathrm{~mm}$ distal to the sleeve sensor. Side holes, spaced at $30 \mathrm{~mm}$ intervals starting at the proximal margin of the sleeve sensor, monitored pressure at seven sites along the oesophageal body. A side hole in the pharynx recorded swallowing. The oesophageal and pharyngeal side holes and sleeve sensor were perfused with degassed distilled water at $0.15 \mathrm{ml} / \mathrm{min}$ and the gastric side hole at $0.08 \mathrm{ml} / \mathrm{min}$.

Proximal gastric function was measured with an electronic barostat (Distender Series II G\&J Electronics Inc., Willowdale, Ontario, Canada) which consisted of a rigid cylinder that introduced or withdrew air from a polyethylene bag positioned in the proximal stomach. The lumina used by the barostat for delivery of air into the bag and sensing of pressure within the bag were incorporated within the manometric assembly. The polyethylene bag had a capacity of approximately $1100 \mathrm{ml}$. The proximal portion of the polyethylene bag was tied to the manometric assembly $60 \mathrm{~mm}$ distal to the sleeve sensor. The cylinder introduced or withdrew air from the bag at $30 \mathrm{ml}$ per second via an oval channel measuring $1.9 \times 2.4 \mathrm{~mm}$ internal diameter (ID) and $1570 \mathrm{~mm}$ in length.

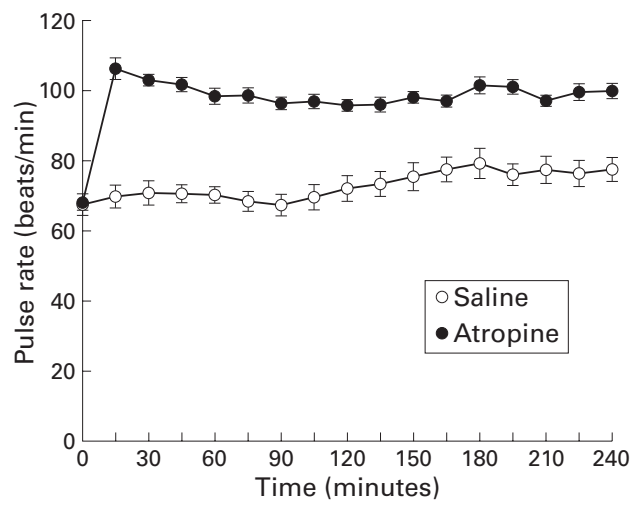

Figure 2 Effect of atropine or saline on heart rate for the duration of the infusion period. Data are expressed as mean (SEM).
Pressure in the bag was sensed via a lumen of $0.6 \mathrm{~mm}$ ID that opened directly into the bag.

Oesophageal $\mathrm{pH}$ was measured with an antimony electrode (Synectics Medical AB, Stockholm, Sweden) positioned $5 \mathrm{~cm}$ above the proximal margin of the LOS.

Data were recorded on a personal computer (PowerPC 7100, Apple Computer Inc., Cupertino, California, USA). Manometric data were digitised at $10 \mathrm{~Hz}$ using a NBMI016 A-D board (National Instruments, Austin, Texas, USA). Barostat data were acquired at $1 \mathrm{~Hz}$ via a serial interface. A custom written program (G Hebbard) using Labview (National Instruments) controlled the barostat and acquired both manometric and barostat data. Data were imported into AcqKnowledge (Biopac Systems, Santa Barbara, California, USA) for subsequent analysis.

ASSESSMENT OF SYMPTOMS

Perceptions of sensations of fullness, nausea, abdominal discomfort, and hunger were quantified using validated $100 \mathrm{~mm}$ visual analogue scales. ${ }^{16}$

STUDY PROTOCOL

Subjects were studied after an overnight fast. A cannula was inserted into the forearm for administration of saline or atropine. The manometric assembly, with the barostat bag folded around it, and the $\mathrm{pH}$ electrode were
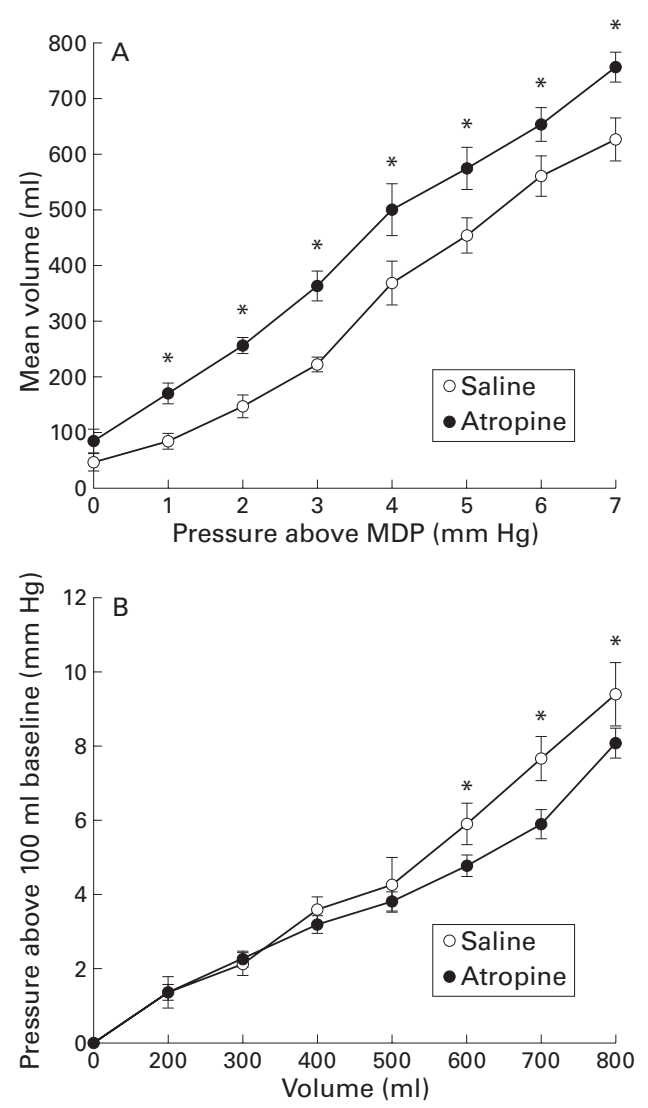

Figure 3 Effect of atropine on the pressure-volume relationship of the proximal stomach during pressure controlled $(A)$ and volume controlled $(B)$ distension. Data are expressed as mean (SEM). ${ }^{*} p<0.05 v$ saline. MDP, minimum distending pressure. 

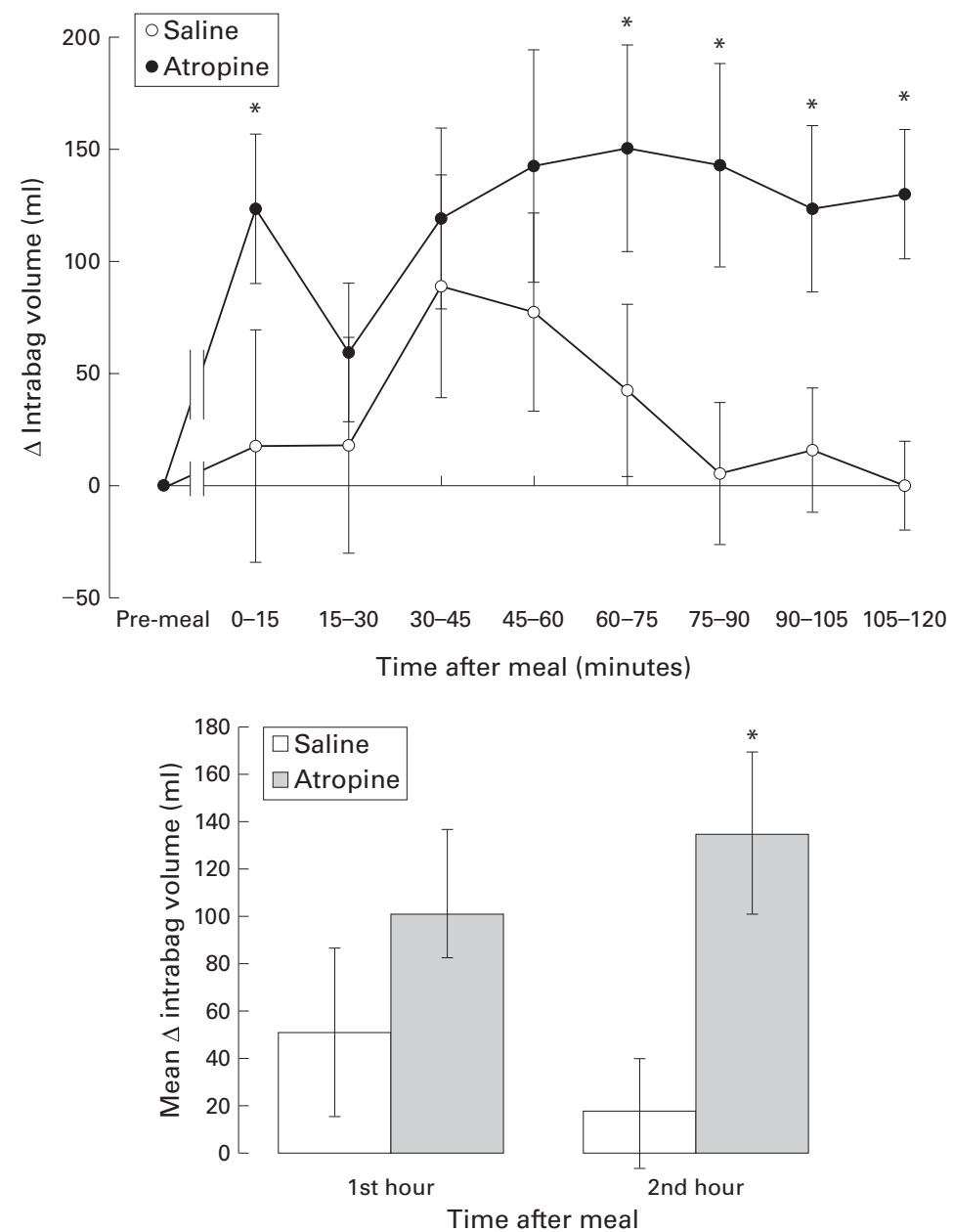

Figure 4 Effect of atropine on postprandial changes in proximal gastric volume. Data are expressed as mean (SEM). ${ }^{*} p<0.05 v$ saline.

passed via an anaesthetised nostril into the proximal stomach. The barostat bag was initially unfolded by inflation with $500 \mathrm{ml}$ of air under controlled conditions (pressure $<20$ $\mathrm{mm} \mathrm{Hg}$ ). The bag was then deflated and the manometric assembly positioned so that the sleeve sensor straddled the LOS, thereby positioning the barostat bag in the proximal stomach. The $\mathrm{pH}$ electrode was then positioned 5 $\mathrm{cm}$ above the proximal margin of the LOS. All studies were performed with subjects sitting upright in an ergonomic chair designed to minimise abdominal compression. Subjects were allowed to accommodate to the manometric assembly for 20 minutes. Intravenous atropine $(15 \mu \mathrm{g} / \mathrm{kg}$ bolus, $4 \mu \mathrm{g} / \mathrm{kg} / \mathrm{h}$ infusion $)$ or saline was then given in random order on separate days and maintained for the duration of the study. During the infusion period, pulse and blood pressure were recorded every 15 minutes.

The minimum distending pressure (MDP), defined as the first intrabag pressure at which the mean intrabag volume was greater than $30 \mathrm{ml}$ and continuous respiratory fluctuations were first detected, was determined. Pressure controlled (isobaric) and volume controlled (isovolumetric) distensions were then performed in random order separated by a 10 minute rest period. During pressure controlled distensions, intrabag pressure was increased in $1 \mathrm{~mm} \mathrm{Hg}$ increments in a stepwise manner every two minutes starting at a pressure $2 \mathrm{~mm} \mathrm{Hg}$ below the previously determined MDP and continued until either an intrabag volume of $800 \mathrm{ml}$ or a pressure of $12 \mathrm{~mm} \mathrm{Hg}$ above MDP, or the threshold for subject discomfort was reached. During volume controlled distensions, intrabag volume was increased in $100 \mathrm{ml}$ increments in a stepwise fashion every two minutes to either $800 \mathrm{ml}$ or the threshold for discomfort. Sensations of fullness, nausea, abdominal discomfort, and hunger were recorded at the end of each distension step.

Following the distensions, subjects rested for 10 minutes. The barostat was then set to maintain a pressure of $2 \mathrm{~mm} \mathrm{Hg}$ above MDP and fasting baseline intrabag volume was recorded for 20 minutes. The bag was then deflated and subjects consumed a $1700 \mathrm{~kJ}$ (400 kcal), $45 \%$ fat, soft mixed nutrient meal, consisting of savoury minced meat, mashed vegetables, milk, and ice cream. The bag was then reinflated to $2 \mathrm{~mm} \mathrm{Hg}$ above MDP and recordings made for another two hours. Sensations were assessed before and every 15 minutes after the meal.

\section{DATA ANALYSIS}

During pressure controlled and volume controlled distensions, mean values for intrabag volume and pressure, respectively, were calculated for the second minute of each distension step, thereby allowing one minute for equilibration. Pressures were expressed as $\mathrm{mm} \mathrm{Hg}$ above MDP. Measured volume was corrected for the effects of air compressibility using an experimentally derived constant which also included a component related to the internal compliance of the barostat unit. Gastric compliance was calculated as the ratio of change of pressure to change of volume in the barostat bag $(\mathrm{d} V / \mathrm{d} P)$ for each individual subject during pressure controlled distension.

Fasting tone was defined as the mean intrabag volume over the last 15 minutes of the 20 minute preprandial observation period. Postprandial changes in gastric tone were determined as change in intrabag volume from mean fasting volume. Maximal postprandial relaxation was defined as the maximal and uniform (variations less than $30 \mathrm{ml}$ ) increase in intrabag volume observed after the meal. ${ }^{17}$

For assessing reflux episodes, acid reflux was defined as a decrease in oesophageal $\mathrm{pH}$ to less than 4 for at least four seconds or, if basal oesophageal $\mathrm{pH}$ was already below 4 , a further decrease in $\mathrm{pH}$ of at least $1 \mathrm{pH}$ unit. When determining the occurrence of reflux during transient LOS relaxation, however, a decrease in $\mathrm{pH}$ of $1 \mathrm{pH}$ unit was used. ${ }^{18}{ }^{19}$ For each reflux episode, the mechanism of reflux was determined from the pattern of LOS pressure and oesophageal body activity, the relationship of these variables to swallowing, and the occurrence of abdominal straining. ${ }^{419}$ Transient LOS relaxations were defined and counted separately according to criteria 

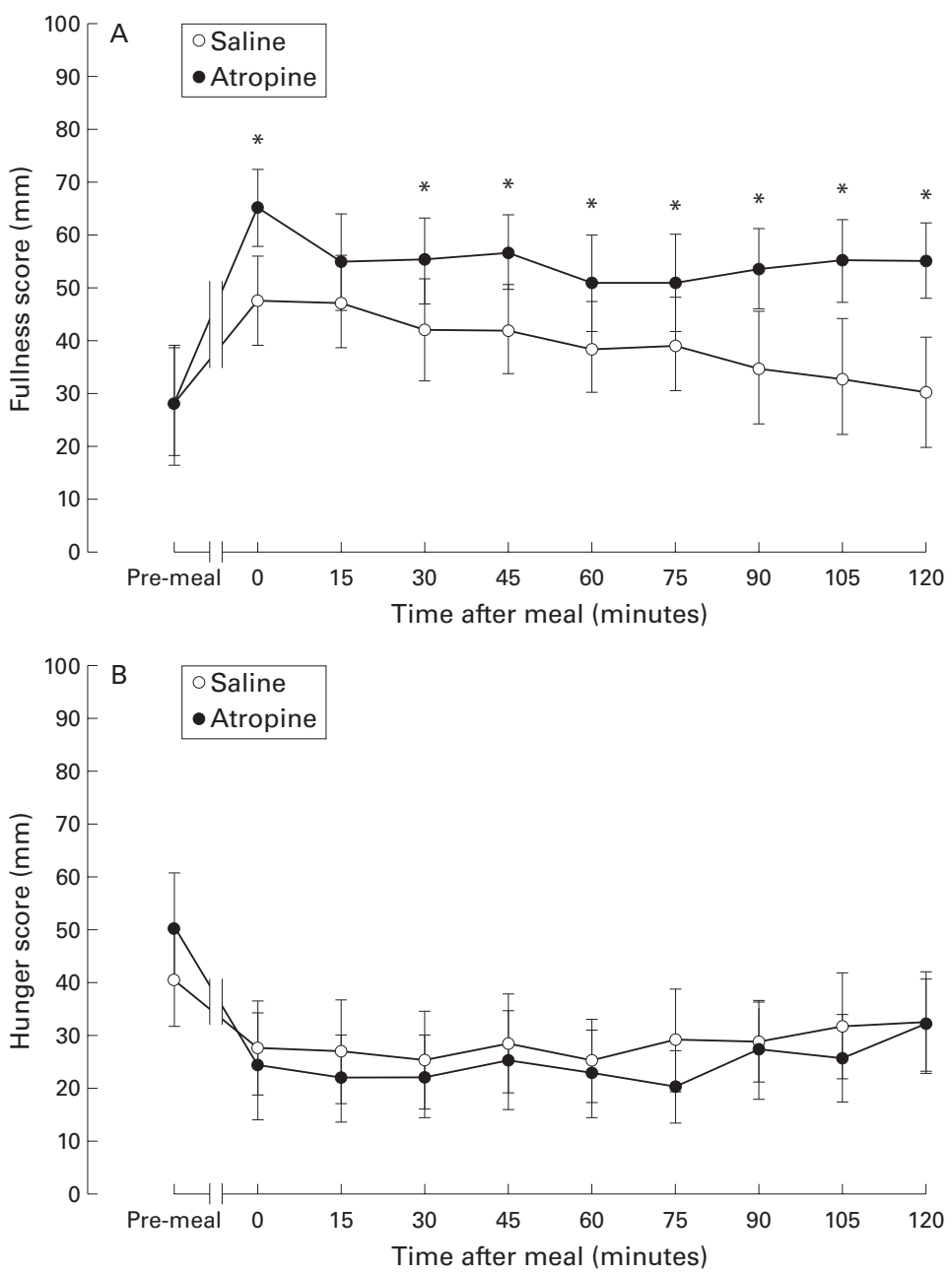

Figure 5 Effect of atropine on postprandial fullness (A) and hunger (B) scores. Data are expressed as mean (SEM). ${ }^{\star} p<0.05 v$ saline.

published previously. ${ }^{20}$ The rate of spontaneous swallowing was determined by counting the number of pharyngeal pressure waves.

STATISTICAL ANALYSIS

Data for intrabag volume and pressure, and sensation scores were analysed using repeated measures analysis of variance (SuperAnova, Abacus Concepts Inc., Berkley, California, USA) followed by paired comparisons where appropriate. Data for reflux episodes and transient LOS relaxations were analysed using the Wilcoxon signed rank test and are presented as median (interquartile range). All other data were analysed using the paired $t$ test and are presented as mean (SEM). A p value of $<0.05$ was accepted as indicating statistical significance.

\section{Results}

All subjects tolerated the study well, and reported symptoms and exhibited signs of cholinergic blockade during atropine infusion. The mean pulse rate during atropine infusion (99 (2) beats/min) was significantly higher than that during saline infusion (73 (3) beats/min; $\mathrm{p}<0.0001$ ) and remained elevated for the duration of the infusion period (fig 2). The rate of swallowing in the postprandial period during atropine infusion (104 (17) per hour) was similar to that during saline infusion (104 (15) per hour).

FASTING RECORDINGS

Atropine significantly reduced fasting MDP from $5.5(0.4)$ to $4.5(0.4) \mathrm{mm} \mathrm{Hg}(\mathrm{p}<0.005)$. However, mean fasting basal intrabag volume at $2 \mathrm{~mm} \mathrm{Hg}$ above MDP during atropine infusion $(234(12) \mathrm{ml}$ ) was not significantly different from that during saline infusion (240 (20) $\mathrm{ml}$ ). Atropine significantly altered the pressurevolume relationship of the proximal stomach. During pressure controlled distension, at each distension pressure from $1 \mathrm{~mm} \mathrm{Hg}$ above MDP, greater volumes were observed during atropine infusion than during saline infusion (fig 3). Consequently, atropine significantly increased calculated compliance $(\mathrm{d} V / \mathrm{d} P)$ of the proximal stomach from 81.3 (5.3) to 102.1 (8.7) $\mathrm{ml} / \mathrm{mm} \mathrm{Hg}(\mathrm{p}<0.05)$. Similarly, during volume controlled distension, at intrabag volumes of $600 \mathrm{ml}$ and above, intrabag pressure was significantly lower during atropine compared with saline infusion (fig 3).

During pressure controlled and volume controlled distensions, sensations of fullness and abdominal discomfort increased in parallel with changes in intrabag volume and pressure. The controlled distensions had no effect on nausea or hunger. Atropine had no significant effect on the level of any of the sensations tested.

POSTPRANDIAL RECORDINGS

Postprandial intrabag volume

Ingestion of the meal was followed by an increase in intrabag volume on both study days. Maximal postprandial volumes achieved during atropine (244 (46) $\mathrm{ml})$ and saline (187 (48) $\mathrm{ml}$ ) infusions were not significantly different. During saline infusion, however, there was almost complete recovery of proximal gastric tone after 90 minutes. In contrast, during atropine infusion, there was no recovery of proximal gastric tone during the two hour postprandial observation period so that in the second hour, mean intrabag volume remained elevated during atropine infusion compared with saline infusion (fig 4).

\section{Sensation scores}

Consumption of the meal was associated with increased fullness scores and reduced hunger scores in both groups (fig 5). Fullness scores paralleled changes in intrabag volume and hunger scores were inversely related to intrabag volume. During atropine infusion, fullness scores were higher than in controls. No significant nausea or abdominal discomfort was reported after the meal.

\section{Transient LOS relaxations}

In the postprandial period, atropine significantly reduced the frequency of transient LOS relaxations in the first and second hours: first hour, $7.0(5.3-10.0)$ per hour $v 3.0(1.0-4.0)$ per hour $(\mathrm{p}<0.02)$; second hour, 5.0 (3.3-5.8) per hour $v 1.0(0-3.0)$ per hour $(\mathrm{p}<0.05)$ (fig $6)$. However, atropine had no effect on the 


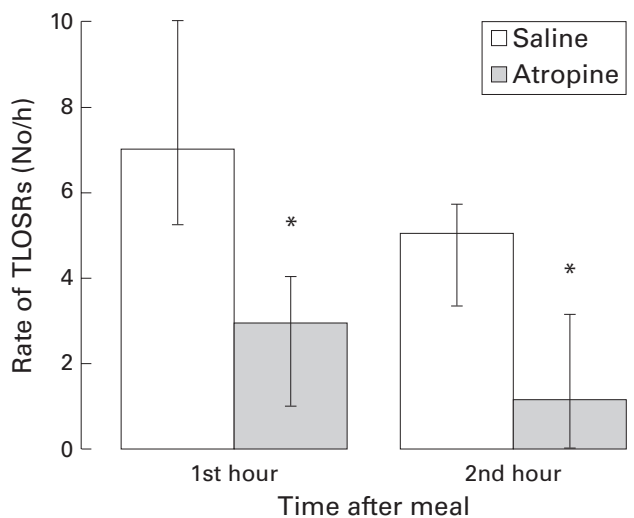

Figure 6 Effect of atropine on the number of transient lower oesophageal sphincter relaxations (TLOSRs). Data are expressed as median (interquartile range). ${ }^{*} p<0.05 v$ saline.

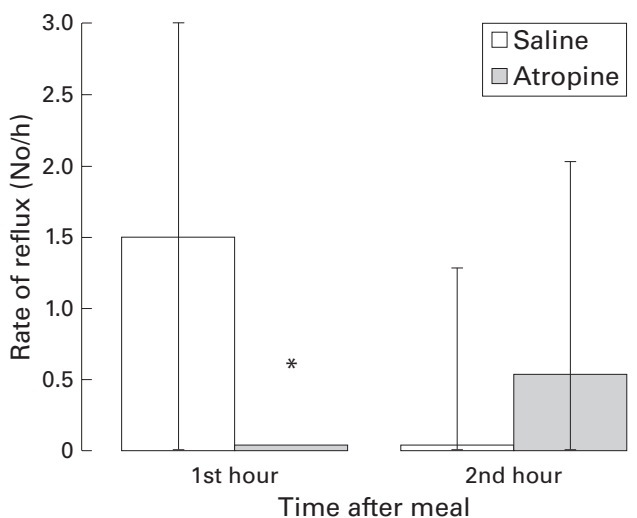

Figure 7 Effect of atropine on the number of postprandial reflux episodes. Data are expressed as median (interquartile range). ${ }^{\star} p<0.05 v$ saline.

proportion of transient LOS relaxations associated with reflux. In the eight subjects who had adequate $\mathrm{pH}$ recordings on both study days, there were a total of 92 transient LOS relaxations during saline infusion, of which 30 $(33 \%)$ were associated with reflux. During atropine infusion there were 41 transient LOS relaxations of which $10(24 \%)$ were associated with reflux.

Reflux

Oesophageal $\mathrm{pH}$ data were available in only eight subjects because of technical problems with the $\mathrm{pH}$ recording system on at least one of the study days in two subjects. In the postprandial period, atropine significantly reduced the rate of reflux episodes in the first postprandial hour $(1.5(0-3.0)$ per hour $v 0(0-0)$ per hour; $\mathrm{p}<0.05)$ but not in the second hour $(0(0-1.3)$ per hour $v 0.5(0-2.0)$ per hour; $\mathrm{p}=0.89)$ (fig 7). During saline infusion, 25 reflux episodes were scored in the eight subjects; 23 were attributed to transient LOS relaxations, one was caused by swallow induced LOS relaxation, and one was during straining. During atropine infusion, seven reflux episodes were scored; five were attributed to transient LOS relaxations and two were due to absent basal LOS pressure.

\section{Discussion}

In this study we have investigated the effects of cholinergic blockade on the function of the proximal stomach in normal human subjects. Our findings indicate that cholinergic blockade significantly inhibits both fasting proximal gastric compliance and postprandial proximal gastric tone.

The reduction in MDP and fasting compliance are consistent with previous findings of the effects of atropine on fasting gastric tone in $\operatorname{dogs}^{10}{ }^{11}$ and cats ${ }^{12}$ and suggest that there is tonic cholinergic input to the proximal stomach. Findings from studies in dogs suggest that this input is vagal. ${ }^{11}$ These previous studies have also reported a reduction in fasting proximal gastric tone as evidenced by increased basal fasting intrabag volume. ${ }^{11}$ We did not observe such an effect. This apparent discrepancy may be due to methodological differences. In the previous study, MDP was determined before administration of atropine and intrabag pressure was set in relation to this pressure. In our study, however, MDP was determined after administration of atropine. Because atropine decreased MDP, basal intrabag pressure during atropine was lower than that during placebo and therefore may have artificially reduced fasting basal intrabag volume relative to that during placebo.

Our findings, however, differ from those of previous studies in normal humans which found no significant effects of atropine on fasting proximal gastric function. ${ }^{13}{ }^{14}$ This discrepancy is likely a result of differences in the doses of atropine used in the previous studies which were substantially lower than in the present study.

Atropine also had a pronounced effect on postprandial motility and effectively inhibited recovery of postprandial proximal gastric tone. Similar effects on insulin induced proximal gastric relaxation have been reported after proximal gastric vagotomy. ${ }^{21}$ It appears, therefore, that return of proximal gastric tone is under cholinergic control. Our findings are at variance with those of the previous studies in humans, ${ }^{13}$ again probably because of differences in the doses of atropine.

Atropine had no effect on the degree of postprandial relaxation, a finding consistent with previous findings in $\operatorname{dog} \mathrm{s}^{10}$ and humans. ${ }^{13}$ Gastric relaxation is mediated by vagal nonadrenergic non-cholinergic inhibitory nerves releasing nitric oxide. ${ }^{22}$ Failure of atropine to influence this response suggests that either the inhibitory stimulus produces maximal relaxation or that cholinergic receptors are not important in the inhibitory pathway. Analogous vagal inhibitory pathways to the lower oesophageal sphincter are similarly not affected by atropine alone but can be almost completely inhibited by a combination of atropine and hexamethonium. ${ }^{23}$

The major impetus for this study was to address the issue of whether atropine might inhibit triggering of transient LOS relaxations by altering proximal gastric tone. Our data do not support this concept. Gastric distension, either by balloons, air or meals, increases the rate of transient LOS relaxations by activation of mechanoreceptors in the proximal stomach, 
particularly in the region adjacent to and involving the cardia. It is not known whether these mechanoreceptors respond to tension or stretch, although current evidence favours the former. Whatever the stimulus, however, under the conditions of this study in which intragastric pressure was maintained constant and slightly above MDP, relaxation of the proximal stomach by atropine would be expected to increase the rate of transient LOS relaxations. We have recently reported a similar finding with sumatriptan, a potent inhibitor of proximal gastric tone. ${ }^{24}$

In this and other studies, ${ }^{7825}$ atropine decreased, rather than increased, the rate of transient LOS relaxations. Our findings are more consistent, therefore, with the notion that atropine reduces the rate of transient LOS relaxations via a central effect on the central pattern generator in the brain stem that is believed to mediate transient LOS relaxations. ${ }^{9}$ Atropine is a non-specific muscarinic antagonist which crosses the blood-brain barrier ${ }^{26}$ and all five of the muscarinic receptor subtypes $(\mathrm{m} 1-\mathrm{m} 5)$ have been detected in the brain. ${ }^{27-29}$ We believe that a central effect of atropine on reducing the rate of transient LOS relaxations outweighs the potential peripheral effects of atropine on the mechanical properties of the proximal stomach which would be expected to increase the rate of transient LOS relaxations.

In a recently reported abstract, Massey et al demonstrated that atropine increased the rate of transient LOS relaxations triggered by gastric air insufflation. ${ }^{30}$ However, subjects were not studied in the postprandial state and intragastric volume was not controlled or measured. It is possible that under the conditions of that study, the peripheral effects of atropine on the proximal stomach in increasing the rate of transient LOS relaxations may have outweighed any potential central effect of atropine on reducing the rate of transient LOS relaxations.

A recent study has shown that perception of gastric distension is a result of increases in gastric wall tension. ${ }^{31}$ Glucagon induced relaxation of the proximal stomach and increased gastric compliance improves sensitivity to pressure controlled distension and decreases sensitivity to volume controlled distension. ${ }^{32}$ In the present study, however, the atropine induced increase in gastric compliance had no effect on the perception scores of fullness, hunger, or abdominal discomfort during the controlled distensions for either pressure controlled or volume controlled distensions. This lack of effect on the sensitivity to distension probably reflects the relatively small effects of atropine on the pressure-volume relationship of the proximal stomach compared with those seen after glucagon administration. ${ }^{32}$ In the postprandial period, fullness scores paralleled changes in intrabag volume. The higher level of postprandial fullness scores during atropine most likely reflects a higher intrabag volume rather than any difference in visceral sensitivity.

In summary, we have demonstrated for the first time that in humans, fasting and postprandial proximal gastric motor function is under cholinergic control. Inhibition of proximal gastric tone by anticholinergic agents may influence triggering of transient LOS relaxations. However, because under the conditions of the study inhibition of gastric tone might be expected to increase rather than decrease the rate of transient LOS relaxations, our findings support the notion that atropine inhibits transient LOS relaxations by a central action on the integrating mechanisms in the brain stem. Further exploration of the central integrating mechanism that triggers transient LOS relaxations is required to help identify future potential pharmacological target sites in the central nervous system.

This work was supported by a project grant from the NHMRC of Australia. Dr Lidums was supported by a Dawes Scholarship from the Royal Adelaide Hospital. The results were presented at the Australian Gastroenterology Week, October 1998, and have been published in abstract form (Fournal of Gastroenterology and Hepatology 1998;13:A135). The authors are grateful to Ms Helen Checklin for technical assistance.

1 Dent J, Dodds WJ, Friedman RH, et al. Mechanism of gastroesophagal reflux in recumbent asymptomatic subjects. $\mathcal{F}$

2 Dodds WJ, Dent J, Hogan WJ, et al. Mechanisms of gastroesophageal reflux in patients with reflux esophagitis. $N$ Engl f Med 1982;307:1547-52.

3 Mittal RK, McCallum RW. Characteristics and frequency of transient relaxations of the lower esophageal sphincter on patients with reflux esophagitis. Gastroenterology 1988;95: 593-9.

4 Dent J, Holloway RH, Toouli J, et al. Mechanisms of lower oesophageal sphincter incompetence in patients with symptomatic gastro-oesophageal reflux. Gut 1988;29. 1020-8.

5 Holloway RH, Hongo M, Berger K, et al. Gastric distension: a mechanism for postprandial gastroesophageal reflux. Gastroenterology 1985;89:779-84

6 Franzi SJ, Martin CJ, Cox MR, et al. Response of canine lower esophageal sphincter to gastric distension. $A m \mathcal{F}$ Physiol 1990;259:G380-5.

7 Mittal RK, Holloway R, Dent J. Effect of atropine on the frequency of reflux and transient lower esophageal sphincter relaxation in normal subjects. Gastroenterology 1995; 109:1547-54

8 Lidums I, Checklin H, Mittal RK, et al. Effect of atropine on gastro-oesophageal reflux and transient lower oesophageal phincter relaxations in patients with gastro-oesophageal reflux disease. Gut 1998;43:12-16.

9 Mittal RK, Holloway RH, Penagini R, et al. Transient lower esophageal sphincter relaxation. Gastroenterology 1995;109: 601-10.

10 Jahnberg T, Abrahamsson H, Jansson G, et al. Gastric relaxatory response to feeding before and after vagotomy. Scand $\mathcal{F}$ Gastroenterol 1977;12:225-8.

11 Azpiroz F, Malagelada J-R. Importance of vagal input in Azpiroz F, Malagelada J-R. Importance of vagal input in maintaining gastric

12 Sifrim D, Coulie B, Tack J, et al. Cholinergic control of the gastric fundus tone. A barostat study in lightly anaesthetized cats. Gastroenterology 1996;110:A758 (abstract)

13 Bruley des Varannes S, Parys V, Ropert A, et al. Erythromycin enhances fasting and postprandial proximal gastric tone in humans. Gastroenterology 1995;109:32-9.

14 Parys V, Bruley des Varannes S, Ropert A, et al. Use of an electronic barostat for measurement of motor response of the proximal stomach to feeding and different nervous stimuli in man. Gastroenterol Clin Biol 1993;17:321-8.

15 Sivri B, Mittal RK. Reverse-perfused sleeve: an improved device for measurement of sphincteric function of the crudevice for measurement of sphincteric function of

16 Horowitz M, Jones K, Edelbroek MA, et al. The effect of posture on gastric emptying and intragastric distribution of posture on gastric emptying and intragastric distribution of terology 1993;105:382-90.

17 Ropert A, Bruley des Varannes S, Bizais Y, et al. Simultaneous assessment of liquid emptying and proximal gastric tone in humans. Gastroenterology 1993;105:667-74.

18 Schoeman MN, Tippett MD, Akkermans LM, et al. Mechanisms of gastroesophageal reflux in ambulant healthy human subjects. Gastroenterology 1995;108:83-91.

19 Penagini R, Schoeman MN, Dent J, et al. Motor events underlying gastro-oesophageal reflux in ambulant patients with reflux oesophagitis. F Neurogastroenterol Mot 1996;8: 131-41.

20 Holloway RH, Penagini R, Ireland AC. Criteria for objective definition of transient lower esophageal sphincter relaxation. Am f Physiol 1995;268:G128-33.

21 Hould F-S, Cullen JJ, Kelly KA. Influence of proximal gastric vagotomy on canine gastric motility and emptying. Surgery 1994;116:83-9. 
22 Desai KM, Sessa WC, Vane JR. Involvement of nitric oxide in the reflex relaxation of the stomach to accommodate in the reflex relaxation of the stomach
food or fluid. Nature 1991;351:477-9.

23 Goyal RK, Rattan S. Nature of the vagal inhibitory innervation to the lower esophageal sphincter. $\mathcal{F}$ Clin Invest $1975 ; 55: 1119-26$.

24 Sifrim D, Holloway R, Missotten T, et al. Sumatriptan maintains the post-prandial increase in transient lowe esophageal sphincter relaxations and increases gastroesophageal reflux in normal subjects. Am $\mathcal{F}$ Gastroenterol 1999;94:3158-64

25 Mittal RK, Chiareli C, Liu J, et al. Atropine inhibits gastric distension and pharyngeal receptor mediated lower oesophageal sphincter relaxation. Gut 1997;41:285-90.

26 Brown JH, Taylor P. Muscarinic receptor agonists and antagonists. In: Hardman JG, Limbird LE, Molinoff PB, Ruddon RW, Gilman AG, ed. Goodman and Gilman's the pharmacological basis of therapeutics, 9th edn. New York: pharmacological basis of therape
27 Brann RB, Ellis J, Jorgensen $\mathrm{H}$, et al. Muscarinic acetylcholine receptor subtypes: localization and structure/function. Prog Brain Res 1993;98:121-6.

28 Caulfield MP. Muscarinic receptors-Characterization, coupling and function. Pharmacol Ther 1993;58:319-79.

29 Levey AI. Immunological localization of $\mathrm{m} 1-\mathrm{m} 5$ muscarinic acetylcholine receptors in peripheral tissues and brain. Life Sci 1993;52:441-8.

30 Massey BT, Narayanan S, Gorney JM, et al. Atropine increases transient lower esophageal sphincter relaxations (TLESRs) if intragastric pressure is held constant. Gastroenterology 1999;116:A4506 (abstract).

31 Distrutti E, Azpiroz F, Soldevilla A, et al. Gastric wall tension determines perception of gastric distension. Gastroenterology 1999;116:1035-42.

32 Notivol R, Coffin B, Azpiroz F, et al. Gastric tone determines the sensitivity of the stomach to distention. Gastroenterology 1995;108:330-6. 